\title{
ANÁLISE COMPARATIVA DA VOLATILIDADE DAS AÇÕES DE EMPRESAS DO SETOR SUCROALCOOLEIRO COM O IBOVESPA
}

ROSSETI, Nara $^{57}$
MEIRELLES, Jorge Luis Faria
VALLE, Maurício Ribeiro do
V9

Recebido em: 2008-07-30

Aprovado em: $2008-08-28$

ISSUE DOI: $10.3738 / 1982.2278 .124$

RESUMO: O presente trabalho tem como objetivo comparar a volatilidade dos retornos das ações de empresas do setor sucroalcooleiro e compará-las ao IBOVESPA. As ações que compõem o estudo são as ações do Grupo Cosan, do Grupo São Martinho e da Açúcar Guarani. Tal análise é importante para que os gestores de portfólios, que tomam decisões de como alocar os investimentos, conheçam o histórico e o corrente relacionamento entre as volatilidades dos ativos. Os retornos foram calculados por meio da diferença do logaritmo neperiano do preço de fechamento diário das ações e do índice. As volatilidades foram calculadas por meio do desvio padrão mensal dos retornos diários. Os resultados mostram que os retornos das ações de empresas do setor sucroalcooleiro são mais voláteis que os retornos do IBOVESPA, na média, mas houve períodos em que uma das empresas apresentou volatilidade inferior ao índice.

Palavras-Chave: Volatilidade. Mercado Acionário. Setor Sucroalcooleiro.

SUMMARY: This paper aims to compare the volatility of stock returns of in the sugar and ethanol companies and compare them to the IBOVESPA. The stocks that make up the study are the shares of Group Cosan, the Group São Martinho and Açúcar Guarani. This analysis is important to the managers of portfolios, which make decisions on how to allocate investments, know the history and current relationship between the volatilities of assets. The returns were calculated using the difference in the Napier's logarithm the closing price on daily stock and index. The volatilities were calculated using the monthly standard deviation of daily returns. The results show that the returns of the shares of companies in the sugar and ethanol companies are more volatile that the returns of the IBOVESPA, on average, but there were periods where one of the companies presented lower volatility compared to the index.

Keywords: Volatility. Stock market. Sugar and ethanol companies.

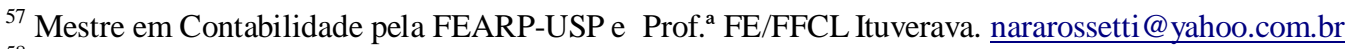

${ }^{58}$ Mestre e Doutorando em Engenharia de Produção - EESC/USC e Prof. de Finanças da UFSCAR - Campus Sorocaba.jorgeluis@ufscar.br

${ }^{59}$ Professor Doutor do Departamento de Contabilidade da FEARP-USP. marvalle@usp.br
} 


\section{INTRODUÇÃO}

A decisão de como alocar uma carteira de ativos depende de duas variáveis, o retorno e o risco estimados. Uma maneira de conhecer o risco de um ativo é medir a sua volatilidade, mais precisamente, verificar qual o comportamento da variação dos retornos deste ativo ao longo do tempo.

Uma das questões mais relevantes em finanças, segundo Jorion (2003), é a questão do risco dos ativos financeiros ao longo do tempo. Para tomar a decisão de como alocar recursos em um investimento, é necessário tentar prever o seu risco, que pode ser obtido a partir da volatilidade dos retornos passados. Nesta linha, assume-se que a volatilidade passada é um bom parâmetro para se inferir sobre a probabilidade de perdas futuras.

Fernandes e Mota (2004) confirmam a grande importância que tem o estudo da volatilidade na área de finanças, em especial no apreçamento de ativos financeiros, como os derivativos, e no gerenciamento de risco. Dario (2004), por sua vez, reforça o entendimento do conceito de volatilidade de um ativo como a medida mais simples para mensurar a incerteza quanto ao seu valor no futuro.

Para se ter uma idéia da importância do setor estudado, vale mencionar que durante a Safra 2005/2006, o setor sucroalcooleiro do Brasil moeu 386,6 milhões de toneladas de canade-açúcar, das quais, em média, metade foi transformada em álcool e metade em açúcar, o que torna o Brasil líder absoluto neste tipo de cultura agrícola (CARVALHO; OLIVEIRA, 2006).

Este trabalho pretende tratar de um ponto ainda pouco coberto para este setor: a análise da volatilidade dos retornos das ações das suas empresas e a comparação com a volatilidade do IBOVESPA, principal indicador do mercado brasileiro de ações. Com isso, o trabalho buscou conhecer o comportamento do preço das ações das Usinas Sucroalcooleiras de capital aberto, cujas ofertas públicas iniciais são relativamente recentes: Cosan Indústria e Comercio S.A. (CSAN3), Grupo São Martinho (SMTO3) e Açúcar Guarani S.A. (ACGU3).

Para o cálculo da volatilidade, utilizou-se a série histórica do preço das ações, do dia de seus lançamentos até o dia 03 de janeiro de 2008, e do fechamento do IBOVESPA dos mesmos dias, todos disponíveis na Economática ${ }^{\circledR}$.

A fim de comparar a volatilidade destes ativos foram utilizados os desvios padrão dos retornos diários para cada série. Como os gestores de portfólios tomam decisões de como alocar os ativos, é valioso conhecer o histórico e o corrente relacionamento entre as 
volatilidades de determinados mercados. Espera-se que este trabalho contribua como uma análise preliminar da volatilidade das ações do setor sucroalcooleiro, bem como auxilie futuramente analistas e gestores do mercado de ações no gerenciamento de seus portfólios.

\section{OS GRUPOS}

\subsection{GRUPO COSAN ${ }^{60}$}

A Cosan expandiu as operações principalmente por meio de aquisições, parcerias e reestruturações societárias desde fevereiro de 2000, quando os acionistas da Irmãos Franceschi Agrícola Industrial e Comercial Ltda, a empresa antecessora, aprovaram um aumento no capital social, em troca da contribuição em capital realizada pelas usinas Costa Pinto, Santa Helena, São Francisco e Tamandupá, com 17 unidades produtoras e dois terminais portuários, em Santos, a COSAN é hoje o maior grupo individual do mundo no que se refere à produção de derivados da cana-de-açúcar. Com capacidade para moer mais de 40 milhões de toneladas de cana, o grupo é responsável por $12 \%$ da produção total do centro-sul do país.

Suas unidades estão todas localizadas no Estado de São Paulo, que apresenta condições ímpares de clima, solo e topografia, o que favorece a COSAN na obtenção de um dos menores custos de produção do mundo. Além disso, a sua infra-estrutura e logística adequadas facilitam o escoamento da produção para os mercados externo e interno. Nos últimos anos, a companhia ampliou seu parque industrial de 3 para 17 unidades produtoras.

Na safra 2006/2007 o Grupo Cosan apresentou um faturamento anual líquido em torno de $\mathrm{R} \$$ 3,6 bilhões, o que proporcionou a geração de 39 mil empregos diretos. O grupo ainda apresenta uma área cultivada de 580 mil hectares e moagem de cana anual de 36,1 milhões de toneladas, o que gerou na safra 2006/2007 uma produção em torno de 64 milhões de sacas de açúcar e 1,322 milhões de $\mathrm{m}^{3}$ de etanol.

Segundo dados da União da Industria da Cana de Açúcar (UNICA) a usina da Barra, empresa do grupo COSAN, foi a maior produtora de cana de açúcar, açúcar e álcool, nas safras 2006/2007 e 2007/2008, o que a torna a maior usina de açúcar e etanol do mundo em capacidade de moagem de cana. Os números apresentados pela UNICA para a Usina da Barra são:

\footnotetext{
${ }^{60}$ Informações extraídas do site www.cosan.com.br
} 
- Safra 2006/2007:

- $\quad$ Toneladas de Cana Moída: 7.018.366

- $\quad$ Toneladas de Açúcar produzidos: 528.674

- $\quad$ M $^{3}$ de álcool produzidos: 289.268

- Safra 2007/2008:

- $\quad$ Toneladas de Cana Moída: 6.815.821

- $\quad$ Toneladas de Açúcar produzidos: 489.723

- $\quad$ M $^{3}$ de álcool produzidos: 290.126

O grupo Cosan é também associado do CTC (Centro de Tecnologia Canavieria), que atua no desenvolvimento de tecnologias inovadoras ao setor canavieiro. As pesquisas do CTC, abrangem os elos da cadeia produtiva de cana-de-açúcar, álcool, açúcar e bioenergia ${ }^{61}$,

\subsection{GRUPO SÃO MARTINHO ${ }^{62}$}

A história da São Martinho teve início na Itália, quando integrantes da família Ometto imigraram para o Brasil, no final do século XIX. No sítio Olaria, montaram seu primeiro engenho de cana-de-açúcar, em 1914. Em 1932, na Fazenda Boa Vista, região de Limeira, a família produziu açúcar pela primeira vez.

Em 1937 foi adquirida a Usina Iracema, em Iracemápolis (SP), a 160 quilômetros da capital, que se transformou em uma destilaria de álcool. Em 1946 a usina também passou a fabricar açúcar. Três anos mais tarde a família Ometto adquiriu a Usina São Martinho, localizada em Pradópolis, a cerca de 330 quilômetros de São Paulo, que se transformou em uma das maiores processadoras de cana do mundo.

Ao longo de décadas as duas usinas cresceram e se modernizaram. Desde o ano 2000 criou-se uma estrutura unificada, para administrar o negócio de maneira cada vez mais profissionalizada, possibilitando novas oportunidades de investimento. Hoje o Grupo São Martinho é um dos maiores do Brasil no segmento sucroalcooleiro e também uma referência mundial na produção de açúcar e álcool.

\footnotetext{
${ }^{61}$ Informações extraídas do site www.ctc.com.br

${ }^{62}$ Informações extraídas do site www.usinasaomartinho.com.br
} 
Atualmente, o Grupo São Martinho é uma organização empresarial com duas usinas de açúcar e álcool em operação e mais uma em construção (Usina Boa Vista), em Goiás, além de uma unidade de negócio em biotecnologia, a Omtek, em Iracemápolis.

De acordo com os dados da UNICA, a usina São Martinho (a maior do grupo) foi a segunda maior unidade produtora de toneladas de cana na safra 2006/2007 e na safra 2007/2008 garantiu novamente o segundo lugar em produção:

- Safra 2006/2007:

- $\quad$ Toneladas de Cana Moída: 6.735.073

- $\quad$ Toneladas de Açúcar produzidos: 499.729

- $\quad \mathrm{M}^{3}$ de álcool produzidos: 286.340

- Safra 2007/2008:

- $\quad$ Toneladas de Cana Moída: 6.762.247

- $\quad$ Toneladas de Açúcar produzidos: 361.580

- $\quad$ M $^{3}$ de álcool produzidos: 336.490

O grupo São Martinho também é associado ao Centro de Tecnologia Canavieira.

\subsection{AÇÚCAR GUARANI ${ }^{63}$}

A empresa teve início na década de 60, na região noroeste do Estado de São Paulo, em Severínia, onde se processava cana-de-açúcar para transformá-la em álcool, aguardente e produtos correlatos.

Um acontecimento decisivo para o ciclo de crescimento que a Guarani viria a protagonizar nos anos 80, 90 até os dias presentes, foi a aquisição da Unidade Industrial Severínia, em 1976, pelo Grupo Gafisa. Naquela época, a unidade produzia etanol e açúcar cristal. O impulso proporcionado pela nova administração logo materializou-se por meio de um novo empreendimento: a construção de uma nova unidade industrial, em 1987, na área rural do município de Olímpia, mais precisamente na Fazenda Cruz Alta, cujo nome foi adotado para identificar a unidade. Esta planta foi a pioneira, no Brasil, na substituição da moenda pelo difusor de cana-de-açúcar.

\footnotetext{
${ }^{63}$ Informações extraídas do site WWW.acucarguarani.com.br
} 
Com administração profissional, a Guarani ganhou reconhecimento internacional e, em julho de 2001, passou a fazer parte do Grupo Tereos.

A Açúcar Guarani S.A. possui como atividade principal a transformação de cana-deaçúcar em açúcar, etanol e energia elétrica, realizada por meio de cinco unidades industriais: Cruz Alta, Severínia, São José, Andrade e Tanabi, no Brasil e a unidade Sena, em Moçambique, na África. A Companhia conta ainda com um projeto greenfield, em Pedranópolis.

A empresa é a terceira maior processadora de cana-de-açúcar e a terceira maior produtora de açúcar do Brasil, além de estar entre as que mais cresceram em produção de etanol nas duas últimas safras, com um processamento de 12,7 milhões de toneladas de canade-açúcar na safra 2007/2008.

A receita líquida de vendas da Companhia, no exercício findo em 30 de abril de 2007, foi de $\mathrm{R} \$ 805,1$ milhões, representando um aumento de $64,4 \%$ sobre o período anterior. $\mathrm{Na}$ safra 2006/2007, moeu o equivalente a quase 10 milhões de toneladas de cana, o que gerou uma produção em torno de 1 milhão de toneladas de açúcar e $200.000 \mathrm{~m}^{3}$ de etanol.

A unidade de Cruz Alta, apresentou os seguintes dados nas safras 2006/2007 e 2007/2008, de acordo com a ÚNICA:

- Safra 2006/2007:

- $\quad$ Toneladas de Cana Moída: 4.052.989

- $\quad$ Toneladas de Açúcar produzidos: 451.326

- $\quad M^{3}$ de álcool produzidos: 64.162

- Safra 2007/2008:

- $\quad$ Toneladas de Cana Moída: 4.168.067

- $\quad$ Toneladas de Açúcar produzidos: 475.664

- $\quad \mathrm{M}^{3}$ de álcool produzidos: 69.275

A empresa Açúcar Guarani é sócia do Centro de Tecnologia Canavieira (CTC) e tem convênios firmados com os melhores institutos e fundações de desenvolvimento e pesquisa de tecnologia de ponta, de renome internacional, como Universidade Federal de São Carlos (UFSCar), Instituto Agronômico de Campinas (IAC), Embrapa, Instituto Biodinâmico e o Instituto Biológico de Campinas (IBC).

Nucleus, v.5, n.2, out. 2008 


\section{REVISÃO DE LITERATURA}

\subsection{O SETOR SUCROALCOOLEIRO}

De acordo com Fregonesi, et al. (2007) nos últimos anos o setor sucroalcooleiro está em voga. Além da questão da capacidade produtiva (o que inclui a qualidade do solo) e da questão do baixo custo de produção, o setor sucroalcooleiro se beneficia pelo fato do álcool ser um combustível renovável, ao contrário da gasolina, combustível fóssil, portanto, esgotável.

Com a criação do Programa Nacional do Álcool (PROÁLCOOL), em 1975, e a obrigatoriedade da mistura do álcool anidro à gasolina, hoje estabelecida em $20 \%$, a produção brasileira de álcool expandiu-se. Outro fato de grande importância é o lançamento, em 2003, por grandes indústrias automotivas, de carros com motores flexíveis (flex fuel), que funcionam com qualquer proporção de mistura de álcool e gasolina. No ano de 2005 as vendas desse tipo de veículo atingiram 50\% do total de veículos leves. Em fevereiro de 2006 as vendas já eram de 76,6\% (CARVALHO; OLIVEIRA, 2006).

Além disso, de acordo com Fregonesi, et al. (2007), com a proposição pelo Protocolo de Quioto de redução dos gases de efeito estufa (GEE), o etanol passa a ser ainda mais valorizado, uma vez que evita a emissão de GEE, gerando créditos de carbono que podem ser comercializados, o que representa mais uma receita para o setor.

De acordo com Camargo Júnior e Toneto Júnior (2008), os principais fatores que têm elevado a demanda internacional por biocombustíveis são: condições favoráveis vividas pelo mercado internacional de açúcar e pelo aumento da procura de etanol em função dos carros flex, além do agravamento das condições climáticas do planeta em decorrência do aquecimento global, a conseqüente busca de fontes energéticas limpas com menor emissão de gases efeito estufa e a elevação significativa do preço do petróleo.

As usinas de açúcar e álcool, especialmente na região Centro-sul, têm plantas industriais modernas e produzem energia com um dos resíduos da produção de açúcar e álcool. O vapor, obtido pela queima do bagaço da cana, movimenta turbinas, gerando energia elétrica que tornam as unidades industriais auto-suficientes. O excedente da energia gerada é vendido às concessionárias para comercialização (CARVALHO; OLIVEIRA, 2006).

Com a desregulamentação do setor, em meados dos anos 90, a venda do excedente de energia elétrica passou a ser importante fator competitivo, pois além de reduzir o custo da produção aumenta a receita de vendas da empresa. Em maio de 2001, o Banco Nacional de 
Desenvolvimento Econômico e Social (BNDES) aprovou recursos de R\$ 250 milhões para financiar a geração de projetos de co-geração a partir do bagaço de cana e, até meados daquele ano, 40 usinas geravam excedentes e comercializavam 300 MW (www.unica.com.br). Atualmente, as usinas de açúcar e álcool geram, para consumo próprio, cerca de 3\% da energia consumida no país, sendo que o excedente comercializado é de 1000 MW (ROCHA, 2007).

\subsection{VOLATILIDADE}

Reilly e Norton (2006) argumentam que os riscos surgem da volatilidade esperada do retorno de um determinado ativo sobre o tempo e que as causas desses riscos são as flutuações da renda estimada, as flutuações na expectativa futura do preço do ativo e as flutuações no retorno do investimento.

Alexander (2005) ainda esclarece que é difícil prever as variações nos preços dos ativos financeiros e, à medida que o prazo aumenta, cresce a incerteza em relação ao retorno destes ativos. Assim, a distribuição destes retornos torna-se mais dispersa, o que implica dizer que eleva a sua variância. A medida mais comum de dispersão é o desvio padrão $(\sigma)$ de uma variável aleatória, isto é, a raiz quadrada de sua variância:

$$
\sigma=\sqrt{\frac{\sum_{i-1}^{n}\left(Y_{i}-\bar{Y}\right)^{2}}{n-1}}, \text { em que: }
$$

$\mathrm{Y}_{i}$ representa o retorno do título, $\bar{Y}$ representa a média dos retornos da amostra e $n$ é o número de observações da amostra ou o número de retornos da amostra.

Chan; Reilly e Wright (2000) realizaram o estudo da volatilidade dos ativos bonds e ações para o mercado americano. Os autores analisaram as mudanças na volatilidade do mercado de bonds e do mercado de ações para um período de cinqüenta anos (de janeiro de 1950 a dezembro de 1999) e as compararam a partir de uma análise estatística temporal. Como medidas de volatilidade foram utilizadas as mudanças dos desvios padrão das taxas de retornos mensais para o período de 12 meses.

Em relação à volatilidade do mercado de ações, alguns estudos exploraram o assunto, como os estudos de Fisher e Lorie (1970), Officer (1973), Schwert (1989, 1990), Jones e Wilson (1989), Ceretta e Costa (1999), Santos (2000), Mota e Fernandes (2004) e Rossetti (2007). 
Fisher e Lorie (1970) consideraram todas as ações da NYSE e examinaram mudanças na variância e na distribuição dos retornos sobre o tempo. Esta foi a primeira análise da variação do mercado de ações sobre o tempo. O desvio padrão e o coeficiente de variação medido pelos autores indicaram que os retornos de mercado durante o período de 1946-1965 foram significativamente menos voláteis que durante 1926-1945, indicando que a maior volatilidade ocorreu por volta dos anos 30 e seguiu após o crash da Bolsa e no período da Segunda Guerra Mundial.

Officer (1973) estudou o período de 1897 a 1969 e conclui que o declínio na variabilidade do mercado de ações, notada por Fisher e Lorie (1970), representa apenas um retorno ao nível normal da variabilidade antes da Grande Depressão de 1930, isto é, a variabilidade do retorno das ações antes de 1930 foi similar à variabilidade depois de 1942, novamente confirmando os períodos que antecederam o crash da Bolsa e durante a Segunda Guerra Mundial.

Schwert (1989) analisou a relação da volatilidade das ações (no período de 1857 a 1987) e a comparou à volatilidade de variáveis macroeconômicas e de outros ativos do mercado financeiro. Alternativamente, a volatilidade do retorno das ações é maior em períodos de recessão econômica, porém mudanças na margem exigida e negociada nos mercados futuros e opções não têm efeito no mercado de ações.

A pesquisa de Schwert (1990) foi mais além em relação ao tempo e examinou a volatilidade das ações listadas na NYSE no período de 1802 até 1989, e se ateve a responder duas questões: o que tem acontecido na volatilidade do preço das ações sobre o tempo? Quais fatores econômicos são relatados para explicar significantes mudanças na volatilidade do preço das ações sobre o tempo?

Nesse trabalho, Schwert (1990) examina e evidencia a volatilidade das ações por dentro da perspectiva de um debate que ocorreu em 1987, ano em que houve o crash do mercado de ações, até 1989, quando aconteceu um declínio do mercado de ações. A análise realizada pelo autor, no período de 105 anos (de 1885 a 1989) (1885 ou 1802?), em que é feito um ranking das variações diárias nos percentuais de retorno, indica que, embora o aumento diário destas variações tenha declinado em 19 de outubro de 1987, quase todos os outros grandes declínios ocorreram de 1929 a 1939. A grande repercussão de 1987, seguida do $\operatorname{crash}$, foi somente o $7^{\circ}$ da lista. Novamente, o grande aumento mensal ocorreu durante a década de 1930.

Jones e Wilson (1989) examinaram o preço diário das ações, de março de 1885 a outubro de 1989, para determinar se o preço das ações, na década de 1980, tornou-se mais 
volátil em virtude do crash de 1987. Eles concluíram que os anos 30 apresentaram um período de maior volatilidade e verificaram, também, que a posição relativa dos anos 80 , comparada a todo o período, depende da medida de volatilidade empregada e do intervalo usado (dias ou meses).

Ceretta e Costa (1999) verificaram a volatilidade do mercado acionário de países da América Latina, na lista dos chamados países emergentes, e constataram que os eventos negativos ocorridos dentro da economia destes países (por exemplo, choques econômicos, crises políticas ou especulação financeira excessiva, característica de países emergentes) impactam mais fortemente a volatilidade do mercado acionário do que eventos positivos.

No estudo sobre a volatilidade e a informação obtida pelos operadores nas negociações das ações, Santos (2000) analisa a série de retornos diários do IBOVESPA e de 28 ações isoladas, cuja ponderação responde por mais de $90 \%$ deste índice, no período de $1^{\circ}$ de julho de 1994 até 30 de junho de 1999, dividido em três subperíodos distintos: 1) implantação do Plano Real (de 01/07/1994 a 30/06/1995); 2) crise da Ásia (01/07/1995 a 30/06/1997); e 3) crise da Rússia e o abandono, pelo Brasil, do regime de bandas cambiais (01/07/97 a 30/07/99). O autor constatou que os retornos apresentaram alta volatilidade no primeiro e último período, e volatilidade moderada no período de 1995 a 1997.

Mota e Fernandes (2004) analisaram a série de retornos diários do IBOVESPA de 01/08/1994 a 24/10/2001 e constaram, a exemplo do estudo de Santos (2000), que o período que apresentou alta volatilidade foi o de dezembro de 1994, provavelmente associado à crise do México. Após outubro de 1997, depois de um longo período de baixa volatilidade com o fim da crise da Ásia, a volatilidade novamente se eleva. Em agosto de 1998, período da moratória da Rússia, ocorreu outro aumento da volatilidade.

Rossetti (2007) analisou a volatilidade do mercado de ações em um período de vinte anos (1986-2006) e a comparo-a à do mercado de renda fixa, no mesmo período. Concluiu que o mercado de ações foi cerca de três vezes mais volátil que o mercado de renda fixa no período de tempo analisado. A autora verificou, também, que a volatilidade dos dois mercados foi superior no período que antecedeu a implantação do Plano Real. Nesse estudo, foram encontrados resultados semelhantes ao estudo de Mota e Fernandes (2004) e Santos (2000), já que nas crises da Ásia e na moratória da Rússia foram encontrados picos de volatilidade no mercado de ações. 


\section{MÉTODO}

Este estudo utiliza o método quantitativo que, conforme definido por Richardson (1999, p. 70), caracteriza-se pelo emprego da quantificação tanto nas modalidades de coleta das informações, quanto no tratamento delas por meio de técnicas estatísticas, desde as mais simples, como percentual, média, desvio-padrão, às mais complexas, como coeficiente de correlação, análise de regressão etc.

Foram utilizadas as séries históricas do preço de fechamento das três ações citadas: da Cosan (CSAN3), da São Martinho (SMTO3) e da Açúcar Guarani (ACGU3), disponíveis na base de dados Economática®. As séries foram compostas desde a data da oferta pública inicial das ações até o dia 03/01/08. Portanto, cada série ficou composta da seguinte maneira: CSAN3 de 18/11/2005 a 03/01/2008 (524 observações); SMTO3 de 09/02/2007 a 03/01/2008 (220 observações); e ACGU3 de 20/07/2007 a 03/01/2008 (111 observações).

Para representar o mercado, foi utilizado o IBOVESPA, conceituado pela BOVESPA (2006) como o valor atual, em moeda corrente, de uma carteira teórica de ações constituída inicialmente em 02/01/1968 (valor-base: 100 pontos), a partir de uma aplicação hipotética. O IBOVESPA retrata não apenas as variações dos preços das ações, mas, por sua metodologia considerar o impacto da distribuição de proventos, também é considerado um indicador que avalia o retorno total de suas ações componentes. A série histórica do IBOVESPA também foi extraída da base de dados Economática ${ }^{\circledR}$. Foi usada uma série de retornos do IBOVESPA para cada ação, em conformidade com as datas e números de observações de cada uma.

O retorno diário dos ativos foi calculado com base no preço de fechamento, utilizando-se a seguinte fórmula:

$$
i_{j, n}=\ln V P_{j, n}-\ln V P_{j, n-1}
$$

em que $i_{j, n}$ é o retorno diário do índice, $\operatorname{lnVP}_{j, n}$ é logaritmo do valor de fechamento do dia $n$, e $\ln V P_{j, n-1}$ é logaritmo do fechamento do dia anterior. O desvio padrão mensal dos retornos diários é, então, dado por:

$$
\sigma=\sqrt{\frac{\sum_{j-1}^{n}\left(i_{j}-\bar{i}\right)^{2}}{n-1}}
$$

Para compor o desvio padrão mensal, foram consideradas sempre 22 observações contínuas, ou seja, 22 taxas de retornos diárias, que é o número médio de dias úteis dentro de um mês, por exemplo: o primeiro desvio padrão foi calculado do dia 1 ao dia 22 da série, o 
segundo do dia 2 ao dia 23 da série, o terceiro do dia 3 ao dia 24 da série e assim sucessivamente. Também foi calculada a correlação dos retornos diários dos ativos, também contando com 22 observações. A correlação é dada pela covariância entre duas variáveis dividida pelo produto dos desvios padrão destas variáveis.

$$
\operatorname{Correl}_{(a, b)}=\frac{\operatorname{Cov}_{(a, b)}}{\sigma_{a} \times \sigma_{b}}
$$

\section{RESULTADO}

\subsection{COSAN - CSAN3}

Conforme observado na Figura 1, os retornos diários da ação CSAN3 e os retornos diários do IBOVESPA possuem movimentos bem semelhantes. Porém, a variação dos retornos da CSAN3 é maior que a variação dos retornos do IBOVESPA, pois enquanto os retornos do IBOVESPA variam numa escala de $-8 \%$ a $6 \%$, as ações da Cosan variam de menos $20 \%$ a $20 \%$, o que sugere um maior risco.

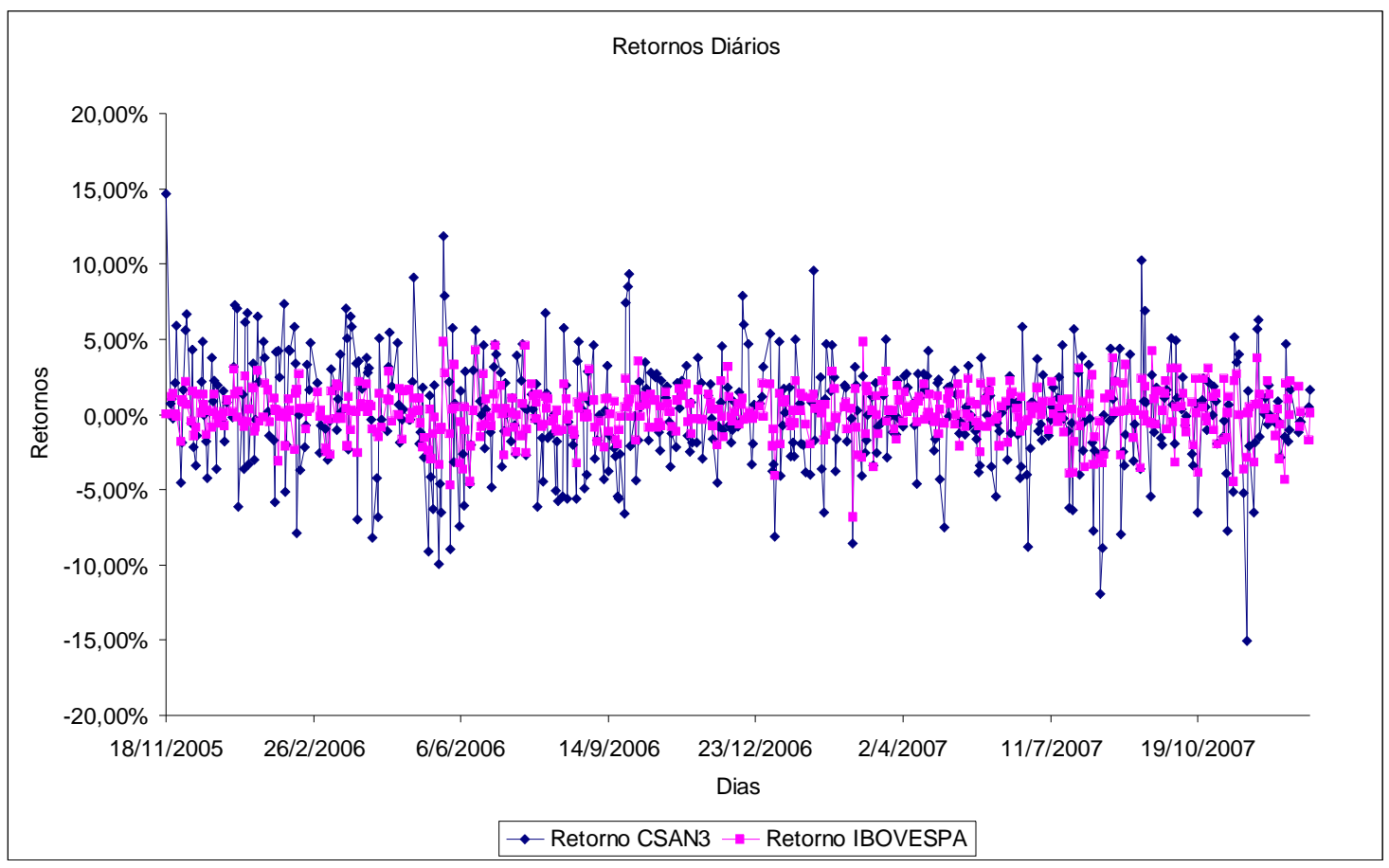

Figura 1: Retornos diários do preço de fechamento da ação CSAN3 e do IBOVESPA (de 17/11/2005 a 03/01/2008)

A correlação dos retornos diários (contando sempre 22 observações, assim como calculado o desvio padrão), das duas variáveis apresentou linha de tendência inear com 
inclinação positiva, o que pode ser entendido que os retornos das duas variáveis envolvidas tendem as ser mais correlatos ao longo do tempo $\mathrm{O}$ índice de correlação em todo o período de tempo analisado para os retornos das duas variáveis foi de 0,51 , conforme demonstrado na Figura 2.

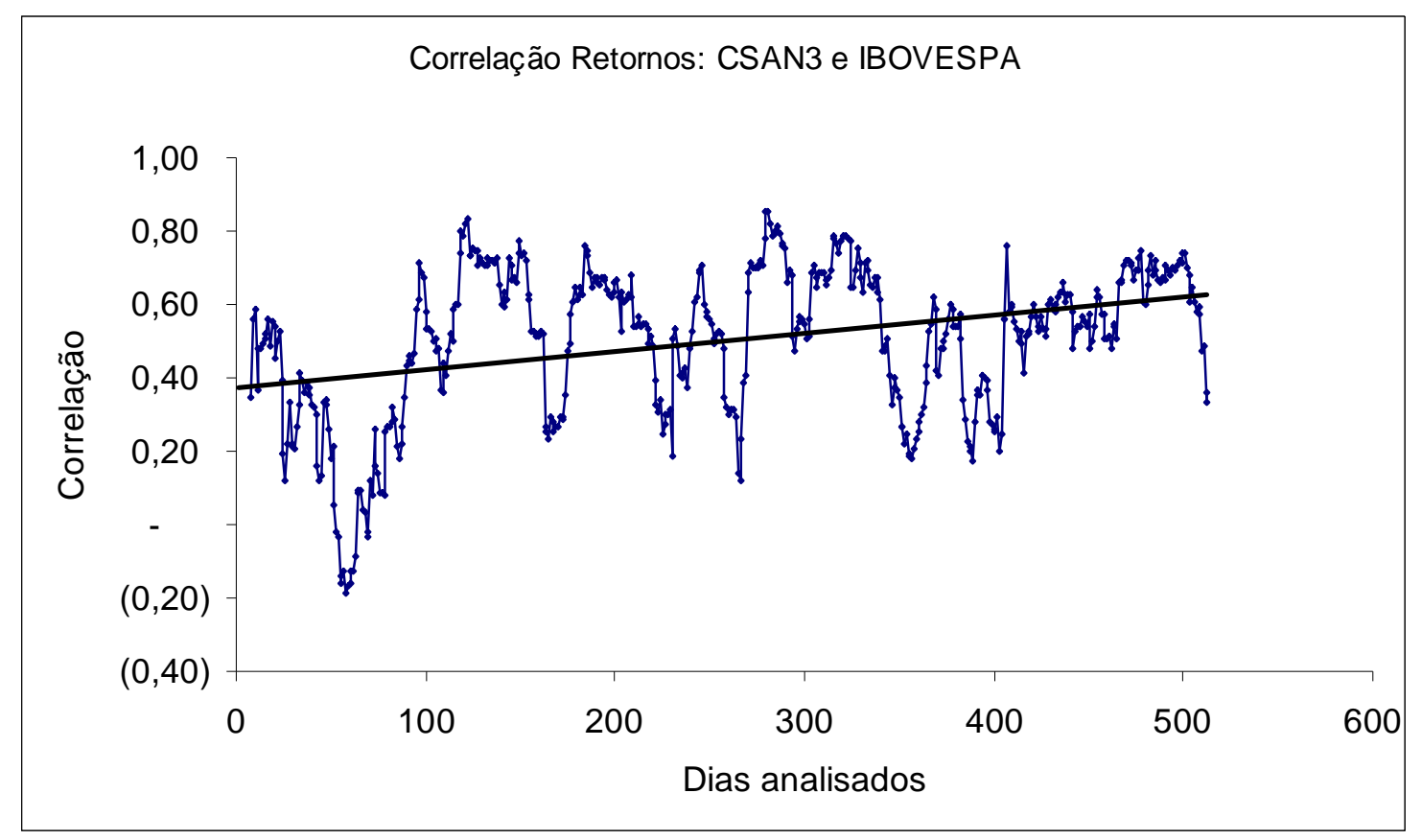

Figura 2: Correlação dos retornos diários do preço de fechamento da ação CSAN3 e IBOVESPA (de $17 / 11 / 2005$ a 03/01/2008)

A Figura 3 demonstra o movimento dos desvios padrão mensal (para 22 dias úteis) dos retornos diários dos dois indicadores do mercado de ações ao longo dos 524 dias analisados. Como já era esperado, devido à maior variação nos retornos, a volatilidade (calculada pelo desvio padrão) da Cosan se mostrou superior à volatilidade do IBOVESPA, e apresentou maiores picos de volatilidade que o índice. A ação da Cosan, além de demonstrar um maior risco que o índice IBOVESPA, apresentou maior retorno no período analisado, o que era de se esperar. 


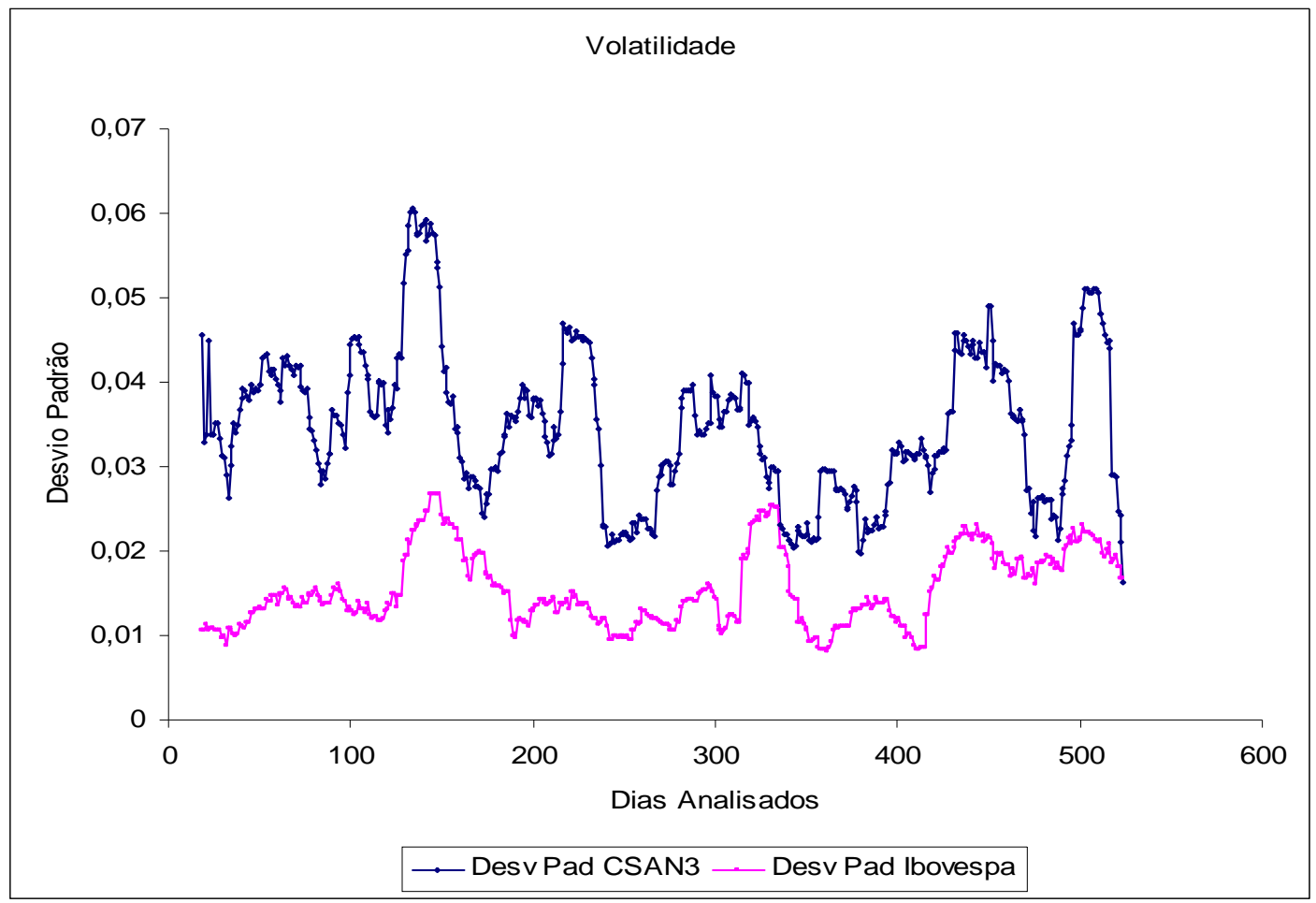

Figura 3: Volatilidade dos Retornos - Desvios Padrão Mensal (de 17/11/2005 a 03/01/2008)

\subsection{SÃO MARTINHO - SMTO3}

A análise das Figuras 4 sugere, a exemplo da ação CSAN3, que os retornos diários da ação SMTO3 variam em uma escala superior aos retornos do IBOVESPA, para a série de 220 dias (09/02/2007 a 03/01/2008). Enquanto os retornos do IBOVESPA se encontram em torno de $-8 \%$ a $6 \%$, os retornos da ação do Grupo São Martinho variam em uma escala em torno de $-10 \%$ a $20 \%$, o que é confirmado pelo cálculo da variância da série. A variância da série dos retornos da ação SMTO3 é de 0,00081 e a variância da série dos retornos do IBOVESPA é de 0,00031 . 


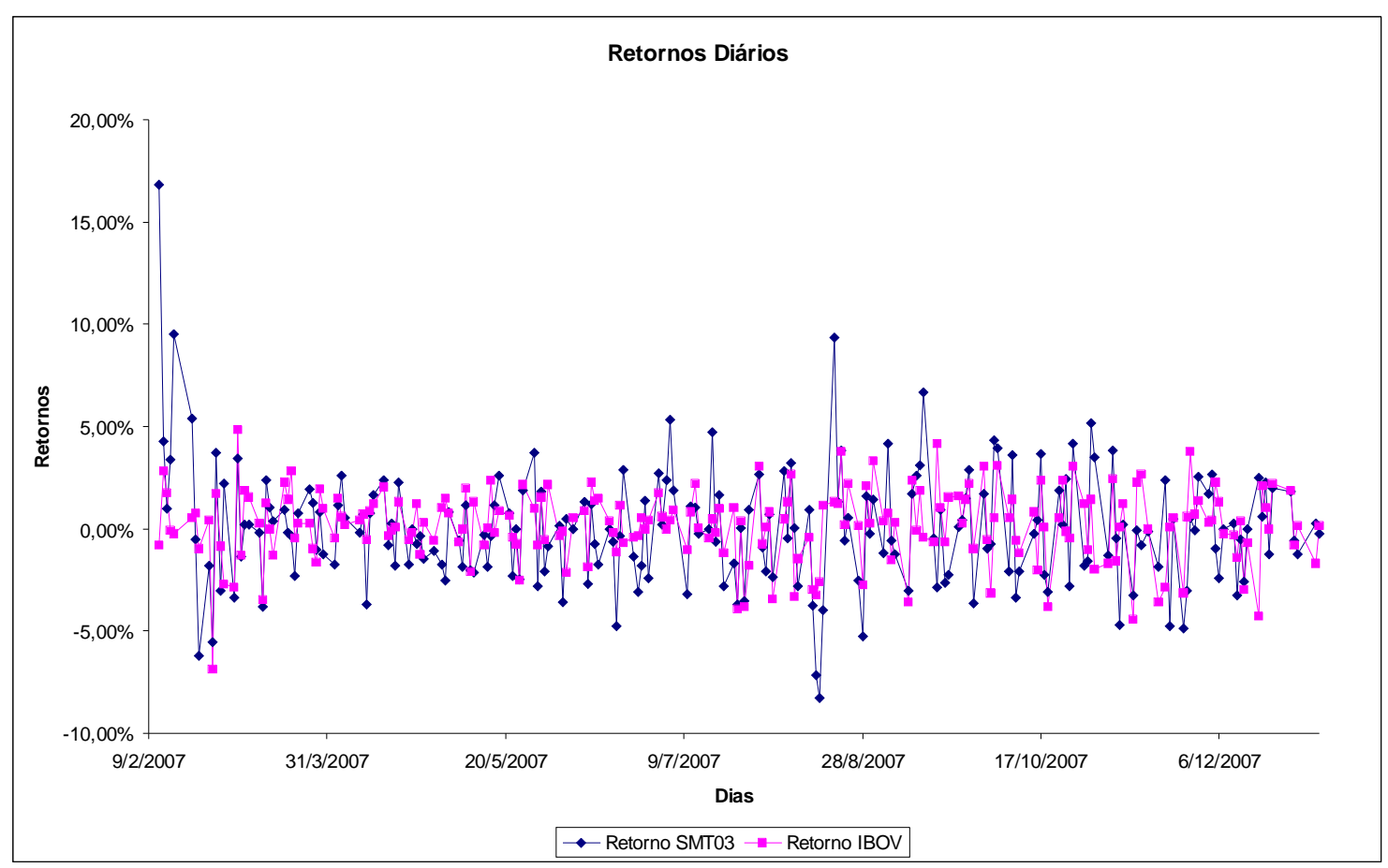

Figura 4: Retornos diários do preço de fechamento da ação SMTO3 e do IBOVESPA (de 09/02/2007 a 03/01/2008)

A Figura 5 demonstra a correlação mensal dos retornos diários dos dois ativos ao longo do período analisado. A linha de tendência negativa sugere que os retornos dos títulos analisados tendem a ser menos correlatos ao longo do tempo. O índice de correlação dos retornos das duas séries, no período analisado, é de 0,42 .

Já a Figura 6 demonstra a volatilidade dos dois ativos, calculada por meio do desvio padrão mensal dos retornos diários. Embora as duas volatilidades possuam movimentos semelhantes no seu padrão comportamental ao longo do tempo, a volatilidade das ações da empresa São Martinho mostrou-se superior à do IBOVESPA, embora tenha se apresentado mais próxima do índice do que as ações do grupo COSAN. 


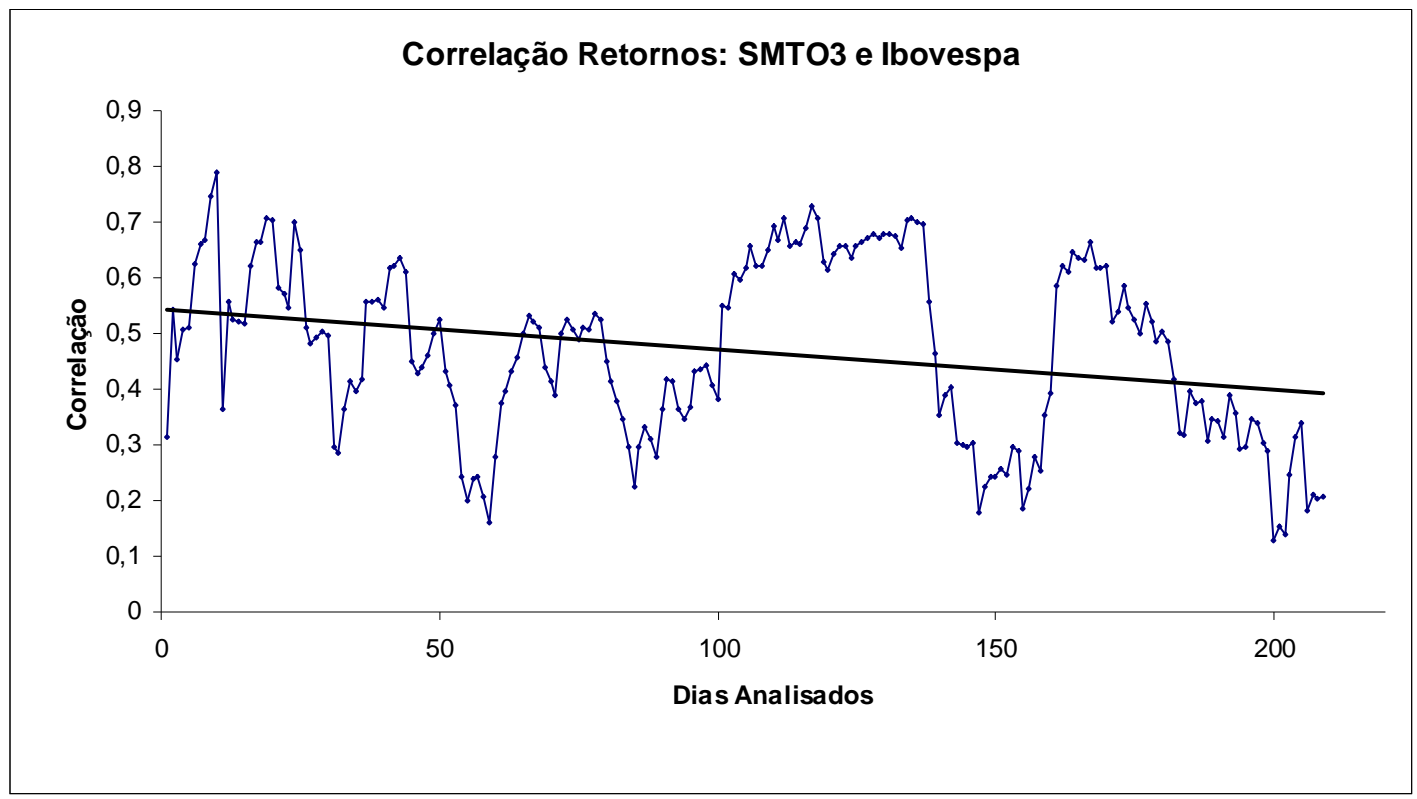

Figura 5: Correlação dos Retornos diários: SMTO3 e IBOVESPA (de 09/02/2007 a 03/01/2008)

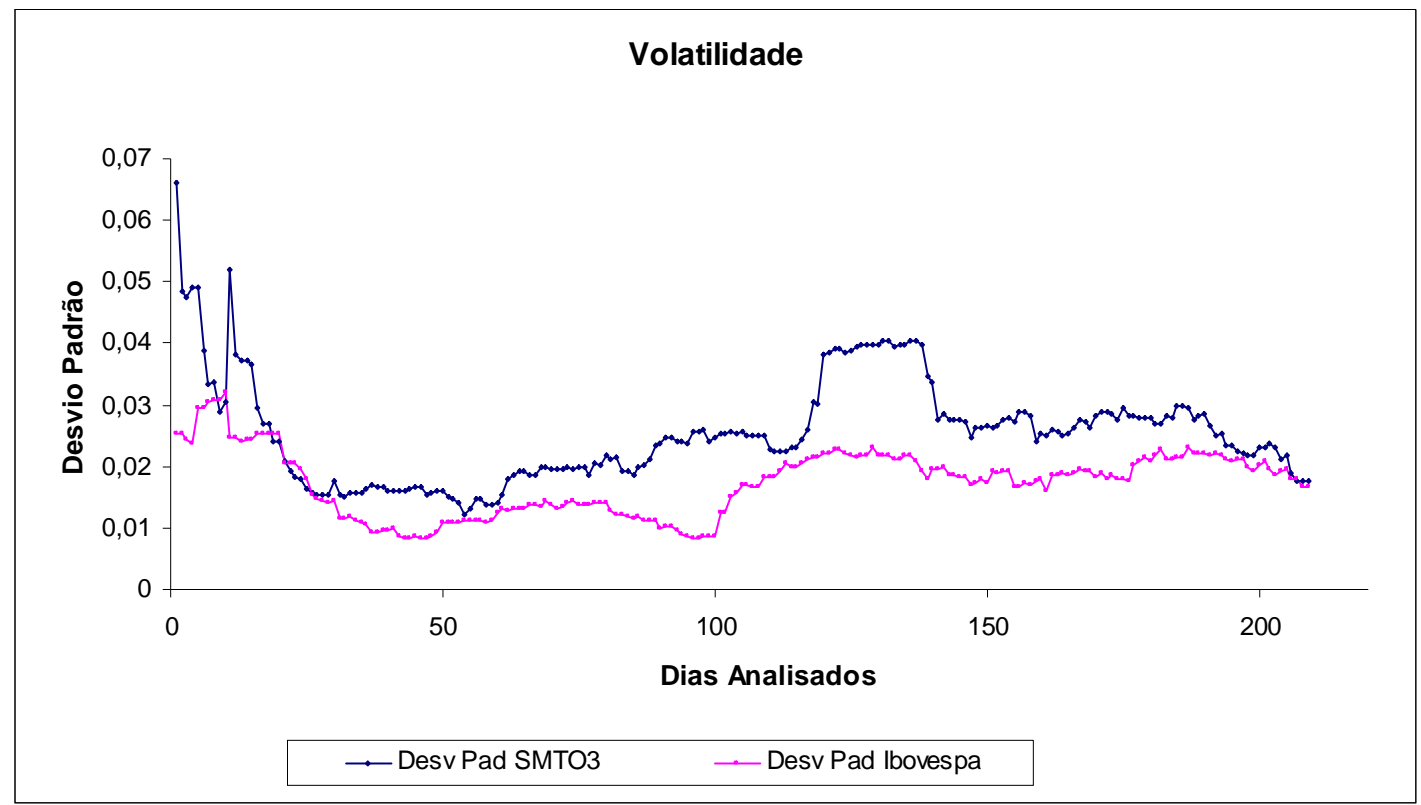

Figura 6: Volatilidade dos Retornos - Desvios Padrão (de 09/02/2007 a 03/01/2008)

\subsection{AÇUCAR GUARANI - ACGU3}

Os retornos da ação do Grupo Açúcar Guarani variaram em uma escala em torno de $-10 \%$ a $10 \%$, enquanto os retornos do IBOVESPA, para o período de 111 observações (de 20/07/2007 a 03/01/2008), variaram em torno de -5\% a 5\%. Embora a variação dos retornos 
da ação ACGU3 tenha se apresentado maior que a variação dos retornos do IBOVESPA, das três ações analisadas (CSAN3, SMTO3 e ACCU3) esta foi a que teve menor variação em escala gráfica, conforme observado na Figura 7, e a que apresentou menor índice de correlação com o IBOVESPA: 0,27.

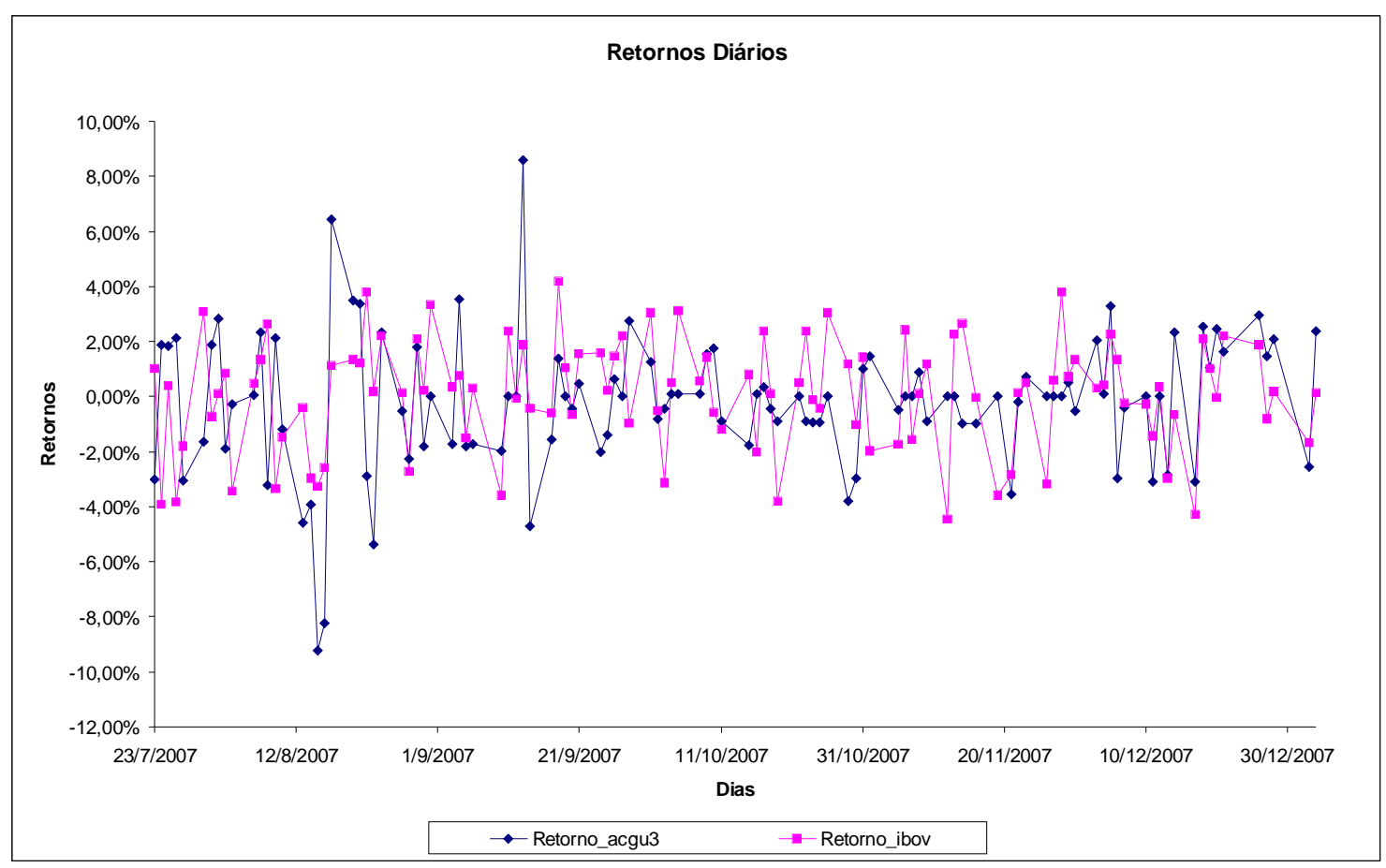

Figura 7: Retornos diários do preço de fechamento da ação ACGU3 e do IBOVESPA (de 20/07/2007 a $03 / 01 / 2008)$

As correlações mensais dos retornos diários da ação ACGU3 com o IBOVESPA, demonstrada pela Figura 8, sugerem que os retornos dos dois ativos tendem a ser mais correlatos ao longo do período analisado, devido à linha de tendência se apresentar inclinada positivamente. 


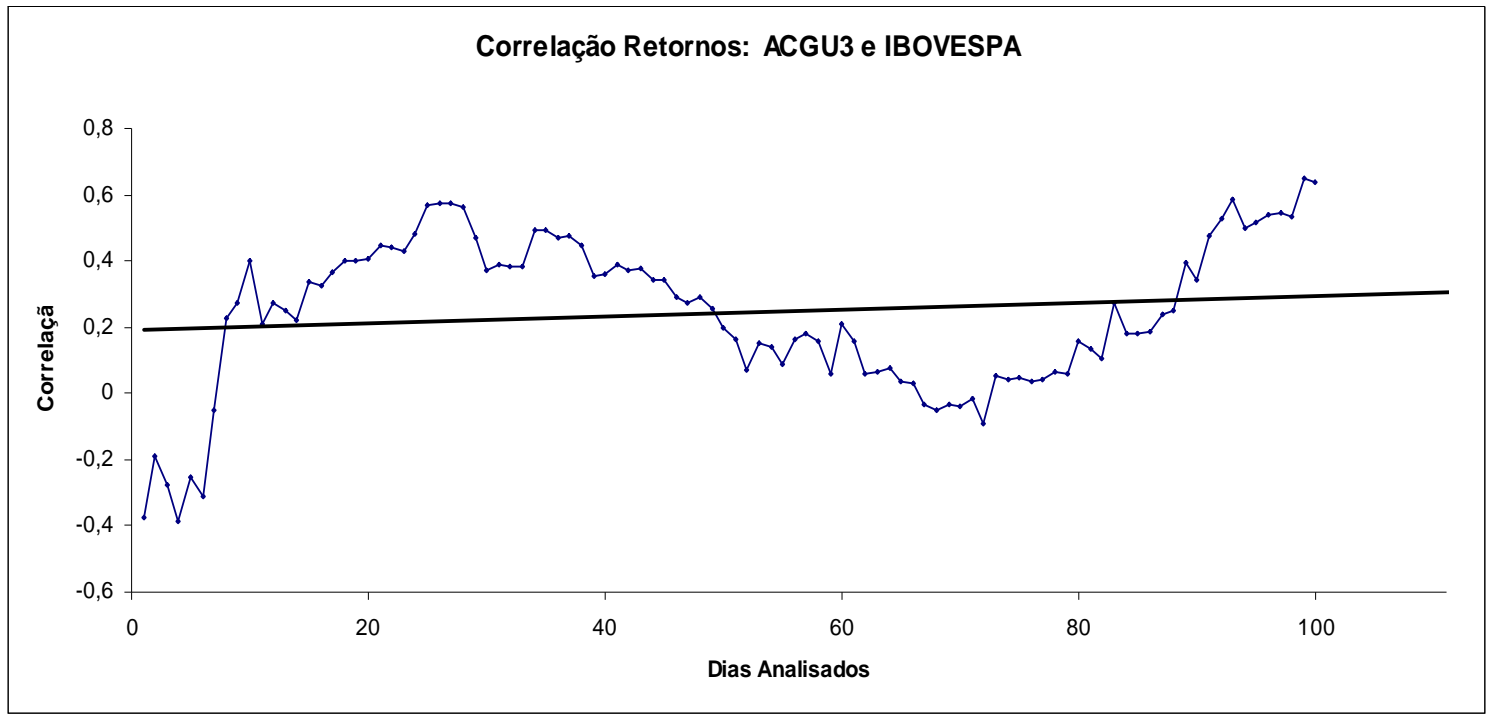

Figura 8: Correlação dos retornos diários: ACGU3 e IBOVESPA (de 20/07/2007 a 03/01/2008)

Já a volatilidade calculada por meio do desvio padrão mensal dos retornos diários da ACGU3 e do IBOVESPA sugere que, diferentemente da volatilidade das ações das outras duas empresas do setor sucroalcooleiro, houve um período em que a mesma foi menor que a volatilidade do IBOVESPA e, ao final do período analisado, as duas volatilidades se apresentam muito próximas, como mostra a Figura 9.

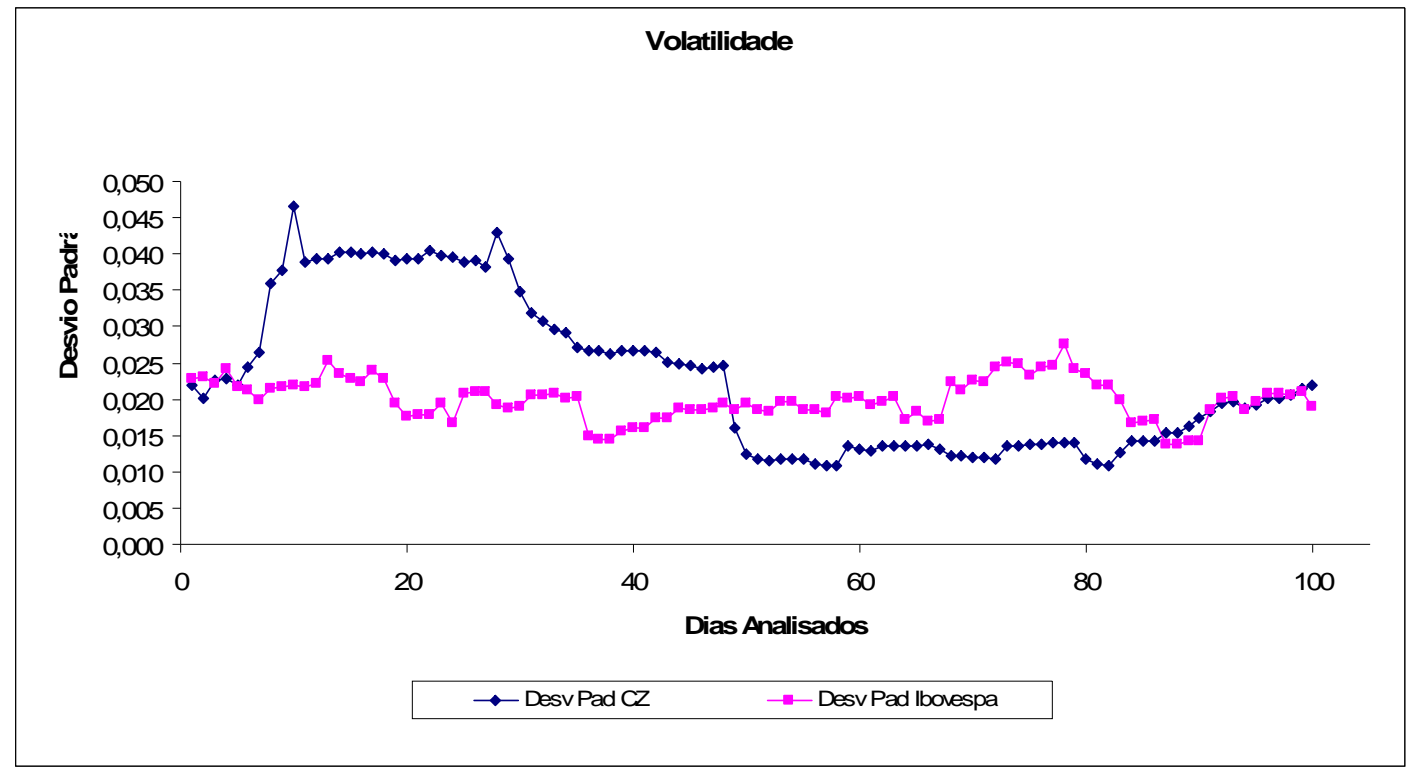

Figura 9: Volatilidade dos Retornos - Desvios Padrão (de 20/07/2007 a 03/01/2008) 


\section{CONSIDERAÇÕES FINAIS}

As variáveis risco e retorno influenciam a decisão de como alocar recursos em uma carteira de ativos. O risco de um ativo pode ser medido por sua volatilidade ou, mais precisamente, pelo comportamento da variação dos retornos deste ativo ao longo do tempo. Este trabalho teve como objetivo analisar a volatilidade dos retornos das ações de três empresas do setor sucroalcooleiro e compará-la ao IBOVESPA. Foram analisadas as ações do Grupo Cosan (CSAN3), do Grupo São Martinho (SMTO3) e do Grupo Açúcar Guarani (ACGU3). Foram estudados os padrões de retorno, a correlação entre os retornos das ações e o IBOVESPA e a volatilidade dos retornos, medida pelo seu desvio padrão.

Embora as ações do Grupo Cosan tenham apresentado movimentos semelhantes ao do IBOVESPA durante o período de tempo analisado, a variação de seus retornos foi maior que o do índice, fato que também ocorreu para os retornos das ações das outras duas empresas analisadas, São Martinho e Açúcar Guarani.

A ação que apresentou maior índice de correlação de seus retornos com os retornos do IBOVESPA foi a CSAN3. Por outro lado, a ação que apresentou menor índice de correlação de seus retornos com os retornos do IBOVESPA foi a ação do grupo Açúcar Guarani. A ação do Grupo São Martinho foi a única que apresentou linha de tendência negativamente inclinada, quando calculada as correlações mensais de seus retornos diários.

A CSAN3 apresentou maiores picos de volatilidade que as ações das outras duas empresas. Tal fato pode ser conseqüência da série temporal da Cosan ser a maior, com 524 dias observados, enquanto a série temporal da SMTO3 contou com 220 observações e a série da ACGU3 com 111 observações. A volatilidade do IBOVESPA e a volatilidade da ação do Grupo São Martinho apresentaram movimentos semelhantes no seu padrão comportamental ao longo do período analisado. A volatilidade das ações da empresa São Martinho mostrou-se superior à volatilidade do IBOVESPA, embora tenha apresentado uma volatilidade mais próxima do índice do que as ações do grupo COSAN. A volatilidade dos retornos da ação da empresa Açúcar Guarani foi a única a apresentar, em determinado período da série analisada, uma volatilidade inferior à do IBOVESPA.

Mais estudos sobre o assunto ainda são necessários, como utilizar um modelo estatístico que capture melhor a volatilidade dos retornos das ações, bem como a ampliação da série temporal, o que não foi possível neste trabalho, por conta das emissões de ações das empresas do setor sucroalcooleiro serem relativamente recentes. Assim, futuramente será possível que mais pesquisas e discussões acerca do assunto surjam e esclareçam de maneira 
mais eficaz o comportamento da volatilidade dos retornos das ações de empresas do setor sucroalcooleiro.

\section{REFERÊNCIAS}

ALEXANDER, C. Modelos de mercado: um guia para análise de informações financeiras. São Paulo: BM\&F, 2005.

CARVALHO, G. R; OLIVEIRA, C. de. O setor sucroalcooleiro em perspectiva. Campinas: Embrapa Monitoramento por Satélite, 2006. 18 p., il. (Circular Técnica, 10). Disponível em: <http://www.cnpm.embrapa.br/publica/download/cit10_sugaralcool.pdf>. Acesso em: 10 mar. 2007.

CAMARGO JUNIOR, A. S; TONETO JR, R. Indicadores Sócio Econômicos e a Cana de Açúcar no Estado de São Paulo. Coletânea de Artigos - Workshop do Setor Sucroalcooleiro. Ribeirão Preto, v. 1, pp. 20 - 34. abr. 2008.

CERETTA, P. S; COSTA JÚNIOR; N. C. A. C. Influência dos eventos negativos e positivos sobre a volatilidade dos mercados da América latina. Cad. Pesq. Adm., São Paulo, v. 1. n. 103, 1999.

DARIO, A. D. G. Apreçamento de ativos baseados em volatilidade: swaps de volatilidadevariância em um modelo de Heston. Resenha da BM\&F, n. 164. Disponível em:http://www.bmf.com.br/2004/pages/instituto/publicacoes/resenha/arquivos/164/artigo02.p df. Acesso em: 18 ago. 2006.

ENDERS, W. Applied Econometric Time Series. Iowa State University: John Wiley \& Sons, Inc: 2004.

FABOZZI, F. Mercado, análise e estratégia de bônus. Rio de Janeiro: Qualitymark, 2000.

FERNANDES, M; MOTA, B. S. Desempenho dos estimadores de volatilidade da bolsa de valores de São Paulo. Rev. Brás. Econ. Rio de Janeiro.jul/set 2004. pp 429-448.

FISHER, I. LORIE, J. H. Some studies on variability of returns on investments in common stock. The Journal of Business, v. 43, n.2 , pp. 99-134, apr., 1970.

FREGONESI, M. S. F. A et al.. Capital structure analysis in brazilian sugar and ethanol companies. In: INTERNACIONAL PENSA CONFERENCE, 6. Anais... 2007

GABE, J; PORTUGAL, M. S. Volatilidade implícita $\mathbf{X}$ volatilidade estatística: uma avaliação para o mercado brasileiro a partir de dados de ações e opções da Telemar S.A. Disponível em: http://www.ufrgs.br/ppge/pcientifica/2003_11.pdf. Acesso em 25/10/06.

GUJARATI, D. N. Econometria Básica. 3 ed. São Paulo: Pearson Makron Books, 2000. http://www.fma.org/Stockholm/Papers/RelativeVolatilityinGermanMarkets_FMA.pdf (2005). Acesso em: 20 jun.2006. 
JONES, C. P; WILSON, Jack W. Is stock price volatility increasing? Financial Analyst Journal. v. 45, n.6, nov./dec. 1989, p. 20.

JORION, P. The long-term risks of global stock markets. Financial management. v. 32, n.4, Winter 2003. p. 5.

LONGSTAFF, F. A; SCHARTZ, E. S. Interest rate volatility and bond prices. Financial Analysts Journal. v. 49, n.4, jul/aug 1993, p. 70

MARÇAL. E. F. Ensaios sobre eficiência, co-intregração, componentes comuns, não linearidades na variância dos mercados financeiros: um estudo da estrutura a termo das taxas de juros e da volatilidade de títulos da dívida externa. 2004. Tese (Doutorado). FEA/USP. São Paulo.

MORAIS, I. A. C; PORTUGAL, M. S. Modelagem e previsão da volatilidade determinística e estocástica para a série do IBOVESPA. Texto para discussão - PPGE/ UFRGS. 1999. n.3.

REILLY, F. K; CHAN, K. C; WRIGHT, D. J. Bond market volatility compared to stock market volatility. Journal of Portfolio Management. v.27, n.1, Fall 2000, p. 82.

REILLY, F. K; NORTON, E. A. Investments. 7 ed. Thomson, 2006.

ROCHA, D. Biomassa pode evitar o aparecimento de novo apagão. Disponível em: <http://www.ambienteemfoco.com.br/?p=2654>. Acesso em 23 abr. 2007.

OFFICER, R. R. The variability of the market factor of the New York Exchange. The Journal of Business. v.46, n.3, jul., 1973, p. $434-453$.

ROSSETTI, N. Análise da volatilidade dos mercados brasileiros de renda fixa e variável no período 1986-2006. 2007. Dissertação (Mestrado). FEARP- USP. Ribeirão Preto.

SANTOS, J. E. Volatilidade do mercado acionário brasileiro: negociação ou passagem do tempo? Um estudo empírico. Resenha da BM\&F, n. 148. Disponível em: http://scholar.google.com.br/scholar?hl=ptBR\&lr=\&q=cache:GwxNo4ekzVQJ:www3.bmf.co m.br/pages/Educacional1/publicacoes/Resenha1/PDFs/Res148/Art04148.pdf+volatilidade+m ercado+a\%C3\%A7\%C3\%B5es .Acesso em 04 ago. 2006.

SCWERT, G. W. Stock market volatility. Financial Analysts Journal. v. 46, n.3, may/jun 1990 , p. 23

SCWERT, G. W. Why does stock market volatility change over time? The Journal of Finance. v. 44, n. 5., dec., 1989, p. 1115-1153.

STOCK, J. H; WATSON, M. K. Econometria. São Paulo: Addison Wesley, 2004.

YOUNG. P. J; JONHSON, R An examination relative volatility in the German Debt an Equity Markets. 29 nov. 2005. Disponível em: http://www.fma.org/Stockholm/Papers/RelativeVolatilityinGermanMarkets_FMA.pdf 
YOUNG. P; JONHSON, R. Bond market volatility compared with stock market volatility: Evidence from the UK. Journal of Asset Management. v. 3, n. 2, sep 2002, p.101.

YOUNG. P. J; JONHSON, R. Bond market volatility vs. stock market volatility: evidence from Switzerland. 2004. Disponível em: http://www.fma.org/Zurich/Papers/570191.pdf. Acesso em: 20 jun. 2006. 